\title{
PREDICTING DETERMINANTS OF USE MOBILE COMMERCE THROUGH MODELLING NON-LINEAR RELATIONSHIPS
}

\author{
Abdullah, H., Thajil, K., Alnoor, A., Al-Abrrow, H., Khaw, K.W., \\ Chew, X.Y., Sadaa, A.
}

Hasan Oudah Abdullah / Basrah University College of Science and Technology, Department of Business Administration, Basrah, Iraq. Email: hasan_oudah@yahoo.com

Krar Muhsin Thajil / Mazaya University, Department of Business Administration, Nasiriyah, Iraq. Email: sha3883@student.usm.my

Alhamzah Alnoor / Universiti Sains Malaysia, School of Management, 11800 Pulau Pinang, Malaysia. Southern Technical University, Management Technical College, Basrah, Iraq. Email: Alhamzah.malik@stu.edu.iq

Hadi Al-Abrrow / University of Basrah, College of Administration and Economic, Department of Business Administration, Iraq. Email: hauni_2000@yahoo.com

Khai Wah Khaw / Universiti Sains Malaysia, School of Management, 11800, Pulau Pinang, Malaysia. Email: khaiwah@usm.my

XinYing Chew / Universiti Sains Malaysia, School of Computer Sciences, 11800, Pulau Pinang, Malaysia. Email:xinying@usm.my

Abdullah Mohammed Sadaa / Universiti Sains Malaysia, Graduate School of Business, Penang, Malaysia.Email: Abdullah1995@student.usm.my

\begin{abstract}
This study aims to predict and assess the antecedents of use social commerce using dualstage structural equation modelling and artificial neural network analysis. This study sheds light on the role of perceived risks in developing the relationship of each of the social bonds and the social network on the convenience of adopting wearable payment. The interactive role of barriers of using the wearable payment for the relationship convenience of adopting wearable payment and intention to use social commerce was also explored. Finally, this study highlighted the effect of the mediating variable of the convenience of adopting wearable payment. The survey was adopted by surveying 334 people with an online shopping experience. The results confirmed the role of interactive variables, perceived risk, and barriers of using wearable payment in increasing intention to use social commerce. On the other hand, the convenience of wearable payment adoption has fully mediated the relationship between social bonds, social network theories and intention to use social commerce.
\end{abstract}

Implications for Central European audience: The findings of this study contribute to providing academics and practitioners with a deep insight into the antecedents of social commerce to develop practices and policies that increase intentions to use social commerce. 
Keywords: social bond theory; social commerce; social network theory; perceived risk; wearable payment

JEL Classification: M1, M2, L2

\section{Introduction}

Social commerce is one of the most important modern issues resulting from the development made in information and communications technology innovation in e-business. Such developments increase the spread of social media technologies (Liang \& Turban, 2011). Interaction between individuals and the virtual community led to the creation of a new opportunity that enabled organisations to exploit Web 2.0 technology to practice social commerce (Lal, 2017). Social commerce is characterised by providing and exploiting the information collected regarding the products and services that customers need. Social media is one of the most common sources of relevant information to enhance the influence of customers' purchasing behaviour (Handarkho, 2020).

Social network refers to the social relationships between actors (Ogan \& Varol, 2016). The social bond essentially refers to the relationship between the individual and society (Shoemaker, 1996). This theory assumes individuals may be associated with emotional bonds or with certain groups and begin to identify them, care for them and desire to continue belonging to them without independence from them (Gardner \& Shoemaker,1989; Durkin et al.,1999). In addition, social network theory makes extensive and significant contributions to explaining the human social organisation (Krause et al., 2007). Since people are strongly affected by the presence of a reference group. In this context, references will compel individuals to accept the modern lifestyle and behaviours. In addition, these pressures lead to maintaining similar behaviours in terms of choosing the goods and the brand preferred by that reference group (Kotler, 1996).

Although social ties and social networks illustrate how individuals tend to behave in similar ways in social commerce, the term wearable payment ease of adoption refers to smart wearable devices that facilitate close communication (e.g. mobile phones, rings, smartwatches, wristbands, eyeglasses, etc.) (Jee \& Sohn, 2015; Lamkin, 2016). The ease of adopting wearable payment increase social commerce intentions. Hence, the adoption of such a method increases the attractiveness of mobile channels, perceived usefulness, ease of use, perceived safety, and trust (Rabaa'i \& Zhu, 2021). With the increasing popularity of smart wearable devices, more than $50 \%$ of consumers in the future are likely to use the smartphone or wearable device for payment processing (Lee et al., 2020).

There is a difficulty in accepting such a method based on new technology. To this end, the study and analysis potential impact of perceived risks and constraints on the use of wearable payment in adopting social commerce is needed. There was a significant impact of perceived risks in adopting social commerce. The risks vary in different forms, including physical, financial, psychological, social, and user privacy (Biucky et al., 2017). In addition, customers tend to respond negatively to innovations, which causes functional barriers represented in the barrier of use due to the changes that can be made to the current situation in violation of previous perceptions.

Moreover, responding negatively to innovations increases the reluctance of individuals to adopt the technology of wearable payment (Ram \& Sheth, 1989; Leong et al., 2020; Nel \& 
Boshoff, 2020). Therefore, increased perceived risks and constraints to wearable payment decrease wearable payment acceptance. This study adopted structural equation modelling approach and artificial neural network (SEM-ANN). To determine the causal relationships between constructs and forecast non-linear and non-compensatory relationships to predict the contribution of supported variables to the dependent variable. The application of the SEMANN approach in the study complements one another because SEM is more suitable for testing the hypothesis with a linear relationship and is inappropriate to deal with the nonlinear relationship. At the same time, ANN implies the opposite as ANN can handle non-linear relationships while it cannot test hypotheses (Albahri et al., 2021; Tan et al., 2014; Hew et al., 2016). The novelty of this study lies in bridging the literature gap by exploring more determinants of social commerce that will contribute to several outcomes for practitioners and academics to enhance such commerce and develop electronic commerce platforms.

\section{Literature review}

This section presents the literature review and hypotheses development. Hence, the following subsection describes the variables of this study to predict and assess the antecedents of using social commerce.

\subsection{Social bond theory}

The social bond is one of the modern concepts proposed to study the influence on social behaviour, although the theory's roots are old. It describes the dynamic processes in which social integration shows a high degree of influence on self-revolving motives (Schroeder, 2016). The Social Bond Theory formulated by Hirschi (1969) consists of four components: participation, attachment, commitment, and belief. Participation refers to the time spent on traditional activities. Attachment reflects the personal level of attachment to family, other people, and peers. An emotional state directed toward others influences behaviour. Commitment refers to the attachment to goals (Akers, 1997; ılırım \& Erbay, 2021). While belief refers to belief in social norms and norms, there is some difference in how individuals believe that they must obey the rules imposed by society. Therefore, the theory should not be understood as a deterrent to violating behaviour as much as it is a theory that explains the individual's behaviour in terms of their association with society (Hirschi, 1969). The social bond theory refers to the relationship between the individual and society (Shoemaker, 1996; Al-Abrrow et al., 2021a; Hamid et al., 2021).

This theory is considered from the positive perspective controlling the behaviour of individuals that prevents deviation if the link that governs that relationship is strong enough on this basis (Durkin et al., 1999; Gardner \& Shoemaker, 1989). However, this theory should not be misunderstood as a deterrent to deviant behaviour. Still, it is primarily explanatory because its role is often limited to social control in an informal way that results from the association of individuals with institutions and groups (Akers et al., 1979; Dull, 1984).

\subsection{Social network theory}

Three aspects of research contributed to the early development of social network theory: the tradition of social analysis, which relies on mathematical methods such as the graph; The interpersonal tradition, which focuses on the groups that form among a group of individuals; and the tradition of anthropology that investigates less developed societies the structure of 
societal relations. These traditions developed at the beginning of the sixties (Burt, 1987; Scott, 1991). Sociologists have made a significant contribution to developing the social network approach, drawing on earlier theoretical traditions to understand and clarify formal and informal social relationships (Abdulaali et al., 2019; Liu et al., 2017).

Social network theory is closely related to influencing individuals and their behaviour. One study indicated that personal influence within social networks becomes stronger the more cohesive those networks are than other less cohesive networks (Friedkin, 1993). It also explains the context of media influences that affect the behaviour of the group and its adoption of a specific behaviour by explaining the role of opinion leaders in this context, as there are two different mechanisms for the social network: the direction of the process of flow first when opinion leaders disseminate information to the group. The other process is contagion and the spread of information through Structural equivalence that supports the group in adopting certain behaviours (Burt, 1999).

\subsection{Perceived risk}

Previous studies contain many different attempts to identify risk based on various assumptions about how perceived risk is identified and how it differs (Jia et al., 1999). Perceived risk can be explained as the feeling of uncertainty that revolves around the possible negative consequences that will occur due to the use of certain products or services. Or it is the result of a combination of risks related to the likely outcome and an aspect of uncertainty (Bauer, 1967; Featherman \& Pavlou, 2003) and the risks of losses related to purchasing operations, which affects the behaviour of individuals, which ultimately hinders the potential buying behaviour (Eneizan et al., 2019b; Peter \& Ryan, 1976). It does not involve real risks, but rather they are risks that arise in the minds of individuals based on their awareness of the variables related to what they face shortly.

Since the perceived risks are primarily affected by the uncertainty that revolves around the consequences of the behaviours that can be implemented, so they are indirectly affected by the variables that increase the factors of uncertainty, for example, disturbance of feelings and annoyance or fear and anxiety (Dowling \& Staelin, 1994), the other thing is The conflict that can be generated from the processes carried out by individuals that affect their behaviour (Bettman, 1973), and the disturbance of feelings and the impact of negative feelings, including on the way they perceive things (Zaltman \& Wallendorf, 1983), (F) which increases the degree of uncertainty experienced by individuals (Engel et al., 1986), and the negative consequences of fear (Taylor, 1974), which magnify the individuals' perceived risk.

\subsection{Convenience of adopting wearable payment}

Wearable Payment Approval refers to the user's adoption of wearable smart devices (e.g. rings, smartwatches, wristbands, mobile phones, etc.) And use it to purchase products and services easily without the limits of time and place in using it for wearable payment (Bezhovski, 2016). The adoption of wearable devices increases with the decrease in the costs of their use and the increase in the efficiency and effectiveness of the performance of modern information communication technologies, as individuals are currently using various types of wearable devices in various aspects of their health and commercial lives (Das et al., 2017; Eneizan et al., 2019a). The payable system and payment method are still constantly evolving. That process makes payments through the touch technology found in wearable devices 
containing a device equipped with wireless transmission technologies (Moeller, 2017; Hadi et al., 2018).

This process and the extent of its dependence depend on the reliability that individuals can feel in its use and the credibility or security permit that restricts users' access and restricts it only to those who have that permit, which is in the form of a password or smart cards, for example (Jin et al., 2004). Authentication is necessary for wearable payment devices in general because it increases the feeling of security as it protects the money from theft if any unauthorised person tries to seize the money and use it without the knowledge of the owner of the money, so the authentication is strong, if it has more than one factor For safety, for example, the use of at least more than one distinct factor (Kaipainen, 2015).

\subsection{Barriers to using the wearable payment}

Resisting innovation is one of the most important obstacles that hinder individuals from adopting new technologies, which can be described as opposition by the consumer to any innovation characterised by events of a state of potential or actual change in the current state of events of contradiction in previous beliefs (Chen \& Kuo, 2017; Ram \& Sheth, 1989). This resistance often occurs by individuals for specific reasons, either because it causes the possibility of changes from the current state of habitual and comfortable use or because it occurs in contrast to the beliefs in which they believe (Alnoor et al., 2021; El Mhamdi et al., 2011; Fadhil et al., 2021).

These barriers increase the more they are contrary to consumer standards or usage habits of routine use or their traditions (Ma \& Lee, 2019). This leaves the majority of individual consumers in a position completely unprepared to adopt such new methods of wearable payment and cling to stability and preservation of the previous situation, which from their point of view appears to be a more typical and rational situation (Alsaleh et al., 2011; Ram \& Sheth, 1989). Because of the bias that tends to support innovations, research has always focused on only one aspect of dealing with the adoption of new and innovative methods that can be adopted by individuals intuitively, but this was at the expense of neglecting the other aspect of the extent to which innovation is accepted and obstacles to its acceptance and use (Enkel et al., 2017; Ma \& Lee, 2019).

\subsection{Intention to use social commerce}

Social commerce is the other side of e-commerce, which refers to social exchange in the practice of commercial transactions that take place through the adoption of social media and other means over the Internet, which allows improving the customer experience in the buying and selling operations that take place over the Internet (Abbas et al., 2021; Abdullah et al., 2021; Alnoor et al., 2020; Beyari \& Abareshi, 2019). Social commerce is one of the modern trends in e-commerce, and one of its advantages is the mixing of social and commercial activities and the exploitation of the integration of the technologies of each (Zhang et al., 2016). Despite its novelty in the commercial arena, it is undergoing continuous and rapid development in practice (Barnes, 2014; Kim \& Park, 2013; Wang \& Zhang, 2012). It is predicted that by 2021 nearly $50 \%$ of the UK population will be involved in social commerce (Lu et al., 2016).

Yahoo was the first to coin the term social commerce in 2005 to refer to the operations that take place over the Internet, where individuals can exchange experiences they have, 
exchange advice with each other, and search for and obtain goods and services and then purchase them (Mardsen, 2010). The popularity of social commerce had increased in conjunction with the increase in the use of social technologies during the past two years, in particular when the popularity and expansion of social media increased in addition to the use of the web and other social networks, which led to the expansion of tools and opportunities for the adoption of social commerce (Khaw et al., 2022a; Liang \& Turban, 2011; Mardsen, 2010). Finally, social commerce can be considered a business process representing a subpart of e-commerce that depends on e-commerce activities for its work (Yadav et al., 2013).

\section{Hypotheses development}

This section describes the development of hypotheses and clarifies the relationships of the conceptual model of this study. Moreover, the first interactive variable, perceived risk, was explained, and the second interactive variable, barriers to using wearable payment, was clarified. In addition, this section includes the development of hypotheses for the mediating variable convenience of adopting wearable payment. According to Albahri et al. (2021a) and Albahri et al. (2021b), who conducted a systematic review of studies that adopted SEM and ANN, there were 60 studies conducted between 2016 and 2021. However, a limited number of studies have investigated the effect of social bond theory and social network theory on intention to use social commerce.

\subsection{The relationship between social bond theory and convenience of adopting wearable payment}

The theory of social bond shows through the four elements that make up the extent of group cohesion in terms of behaviour and goals for psychological and emotional reasons that may seem logical from the point of view of individuals (Khaw et al., 2022a; Lee et al., 2020). This allows the formation of a strong social bond that restricts and controls the behaviour of the members of the group in an emotional way that does not want to be independent of it and a psychological commitment with it so that individuals are afraid of severing that bond and separating from that group to avoid the emotional pain that can occur due to the severing of that relationship (Durkin et al.,1999; Gardner \& Shoemaker,1989; Krishnan et al., 2021). Recently, these groups have become more active through virtual reality, which is represented by social media, especially with the increase in the popularity of these means to conduct commercial transactions (Khaw et al., 2022b; Liang \& Turban, 2011; Mardsen, 2010). And the use of modern technological techniques to complete these commercial transactions by developing special technologies that allow the possibility of a wearable payment in which bracelets, mobile phones or smart cards are used (Bezhovski, 2016). Which is usually characterised by the reliability and safety it can provide to users, which firmly establishes the element of belief and commitment in the social bond in that field (Akers, 1997; Kaipainen, 2015; ıldırım \& Erbay, 2021). As a result, the following hypothesis was developed:

H1: The social bond theory is positively related to adopting wearable payment.

\subsection{The relationship between social network theory and convenience of adopting wearable payment}

The social network is characterised by a special pattern that governs the behaviour of individuals by defining the pattern and strength of relationships within the group, in addition 
to defining the main roles of some people who represent the main leaders (Boyd \& Crawford, 2012; Ogan \& Varol, 2016). Social networks have been active in recent times through technological techniques, especially in exploiting social networks (e.g. Twitter). The roles of chiefs are active in influencing the behaviour of individuals in social networks (Earl \& Kimport, 2011; Lewis et al., 2013). Many technologies have also appeared, which have enhanced the influx of individuals to use them widely, allowing them to be exploited in facilitating commercial transactions, which created a new trend in the business world (Chuah et al., 2016). It led to a radical change that took large groups of individuals with them towards a new world around the technology used personally (Lee et al., 2020). In terms of reducing the effort and time required to make payments, in addition to the means of safety that can create a positive impression in which individuals affect each other's behaviour, which creates a similarity in the group's behaviour towards its use (Borowski et al., 2020; Jeong et al., 2017).

H2: The Social network theory positively relates to the convenience of adopting wearable payment.

\subsection{The relationship between convenience of adopting wearable payment and intention to use social commerce}

Social trade activity is increasing through modern technologies represented by social media, which links sellers and buyers, whether in newly emerging markets or mature markets (AlAbrrow et al., 2021a; Handarkho, 2020). By reviewing the concept of social commerce, we find that social commerce works to meet the need for the lack of adequacy of human and financial resources, especially in the information technology sector, which depends mainly on two main points: facilitating simple interactions and reducing costs between the seller and the customer (Braojos et al., 2019; Gibreel et al., 2018). New technologies are facilitating online community creation and their interactions, allowing communities to access important information, exchange opinions and experiences, and obtain advice from peers, thereby influencing purchase decisions and buyers' behaviour (Chen \& Shen, 2015; Shanmugam et al., 2016; Sharma et al., 2018). Specifically, wearable payment relies on smart devices to facilitate business processes and reduce costs associated with those operations (Albahri et al., 2022; Bezhovski, 2016). This leads to the cohesion of the user communities to increase their desire to adopt the social trade that takes place through it, especially with its association with highly reliable safety systems (Moeller, 2017).

H3: The convenience of adopting wearable payment is positive related to intention to use social commerce.

\subsection{Mediating role of the convenience of adopting wearable payment}

Social network theory and social bond theory show the extent of individuals' commitment and compliance in terms of their behaviour within the group, which is proven through the influence of the head leaders. The roles of power and the pattern of relationships characterise social network theory behaviour (Boyd \& Crawford, 2012; Ogan \& Varol, 2016), and the elements of social bond theory represented by participation, attachment, belief and commitment, the components that constitute its basic building block (Akers, 1997; ılırım \& Erbay, 2021). In an emotionally attractive way, individuals strive to maintain that social bond between them (Alhamdi et al., 2019; Schroeder, 2016). This increases the cohesion of individuals with each 
other. The matter develops into adopting the group behaviour and perhaps making concessions on some behaviours to avoid the psychological pain from leaving the group (Durkin et al.,1999; Gardner \& Shoemaker,1989). Social networks and the social link are actively active in social networks to conduct commercial transactions easily (Earl \& Kimport, 2011; Lewis et al., 2013; Tariq et al., 2021). The exchanges and procedures of commercial transactions used by society refer to social commerce that occurs through social media and the exploitation of virtual networks over the Internet in conducting those transactions (Beyari \& Abareshi, 2019) by combining commercial and social activities simultaneously (Zhang et al., 2016). This prompted the development of many technologies that achieve that link between society and social commerce to facilitate commercial transactions represented by wearable payment technologies (Das et al., 2017), which in turn represented the key to individuals' access to social commerce, especially with its contribution to reducing commercial transaction costs and increasing safety (Atshan et al., 2021; Moeller, 2017).

H4: Convenience of wearable payment adoption mediates the relationship between social bond theory and intention to use social commerce.

H5: Convenience of wearable payment adoption mediates the relationship between social network theory and intention to use social commerce.

\subsection{Moderator role of perceived risk}

Studies indicate that the main link in the adoption of social networks and the interaction of the social link with social commerce comes through modern technologies (wearable payment technologies) (Das et al., 2017; Earl \& Kimport, 2011; Lewis et al., 2013). The public's adoption of wearable payment devices is increasing based on criteria whose availability is an absolute necessity for their use, namely facilitating the conduct of commercial transactions first, reducing the costs of those transactions, and the reliability and security that can be provided by the use of such technologies (Earl \& Kimport, 2011; Lewis et al., 2013; Moeller, 2017). This indicates how important it is for individuals to see the level of perceived risk.

Perceived risk has a long and varied research history; however, many researchers have not recognised the prevalence of the concept and its influence on individuals' behaviour, especially in the buying process. Cunningham was the first to suggest that perceived risk revolves around two main causes: uncertainty and the other reason being the consequences of decision-making (Alnoor et al., 2022; Cunningham, 1967; Mitchell, 1992). Those consequences can range from psychological consequences to social consequences. The consequences do not stop there, but there are other types of consequences, which can be slapped with, for example, physical consequences, safety consequences, financial consequences and time (Jabbar et al., 2020; Mitchell, 1992; Perry \& Hamm, 1969; Roselius, 1971).

H6: The relationship between social network theory and intention to use social commerce would be strong when perceived risk is high.

H7: The relationship between social bond theory and intention to use social commerce would be strong when perceived risk is high. 


\subsection{Moderator role barriers of using the wearable payment}

Social commerce is expanding and growing in popularity due to its close association with many modern online technologies (for example, social media and wearable payment devices) that can be applied in markets regardless of market age and maturity (Beyari \& Abareshi 2019; Handarkho, 2020). Which works based on meeting two basic needs, namely, first, facilitating commercial transaction procedures in terms of time and effort, and secondly reducing costs related to conducting commercial transactions between the seller and the buyer (Braojos et al., 2019; Gibreel et al., 2018; Liang \& Turban, 2011; Mardsen, 2010). In addition to the contribution of these technologies in facilitating the community's access to important information related to the business operations they are looking for, as well as their interaction with each other, allowing them to exchange opinions and experiences to make decisions based on the advice taken from others (Chen \& Shen, 2015; Shanmugam et al., 2016; Sharma et al., 2018). Wearable payment technologies allow meeting those needs associated with social commerce through the diversity of its technologies that harmonise the different visions of individuals, leading to an increase in the desire of individuals to adopt social commerce (Bezhovski, 2016; Jee \& Sohn, 2015; Lamkin, 2016; Moeller, 2017). However, the barrier of resistance to innovation significantly weakens that relationship by weakening the confidence of individuals in using modern technologies, which makes them reluctant to adopt them (Chen \& Kuo, 2017; Ram \& Sheth, 1989). Especially if the use of these technologies is modern and in opposition to the traditional beliefs of individuals, with the consequences of using them ambiguous (El Mhamdi et al., 2011), this leads to the reluctance of individuals to use payable payment devices to conduct commercial transactions (Alsaleh et al., 2011; Ram \& Sheth, 1989). Figure 1. illustrates the conceptual framework of this study.

H8: The relationship between the convenience of adopting wearable payment and intention to use social commerce would be strong when barriers to using wearable payment are weak.

Figure 1 | Conceptual framework

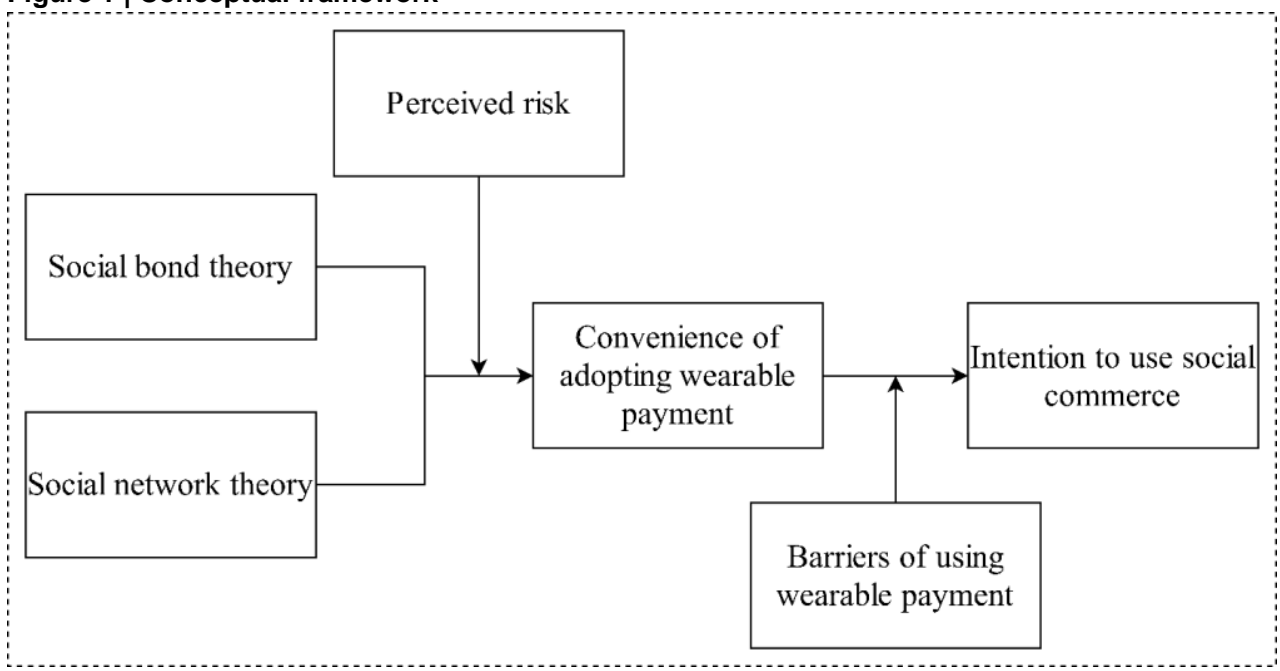

Source: authors' own elaboration 


\section{Methodology}

A sum of 334 social commerce users in Iraq was collected. In addition, this study adopted a filter question, "Do you use social media to buy online" to identify customers who have experience with online transactions. Furthermore, the online survey has been conducted due to COVID-19 restrictions that have forced the closure of many countries. The sample size is considered suitable for this study because the sample size must be ten times of formative indicators used; or ten times of paths directed in the structural model (Hair et al., 2011). The demographics of the respondents were $39 \%$ males, $61 \%$ females; $34 \%$ between the ages of 15 and $24 ; 31 \%$ between the ages of 25 and $34 ; 20 \%$ between the ages of 35 and $44 ; 9 \%$ between the ages of 45 to 54; and 6\% between the ages of 55 and 64 . There are $19 \%$ with a high school diploma, 27\% with a diploma, 37\% with a bachelor's, and 17\% with postgraduate. Regarding online shopping, $46 \%$ of respondents used Facebook, $24 \%$ of the Instagram, 15\% used WhatsApp, 6\% Google and 9\% Twitter.

This study adopted a 5-point Likert scale because many points confuse respondents in filling out the questionnaire (Alnoor et al., 2021). Social bond was measured using four items (e.g., I have a very strong friendship with this social commerce firm) (Shanka \& Buvik, 2019). The social network was measured utilising 12 items (e.g. I think that buying things over the Internet is a good idea) (Akar \& Dalgic, 2018). Perceived risk was measured by adapting five items (e.g. I would not feel safe providing personal private information over mobile services) (Akar \& Dalgic, 2018). Barriers to using wearable payment were measured by adapting 17 items (e.g. Wearable payment is convenient because I can use it anytime) (Kaur et al., 2020). The convenience of adopting wearable payment was measured by adapting five items (e.g. I intend to purchase wearable devices) (Jeong et al., 2017). Intention to use social commerce was measured by adopting five items (e.g. I feel fine interacting with the social network community because it fulfils my needs of interaction efficiently) $(\mathrm{Ng}, 2013)$.

To investigate the impact of social theories on the adoption of social commerce, Partial Least Squares Structural Equation Modeling (PLS-SEM) was adopted. PLS-SEM method contributes to establishing causal relationships between variables. Furthermore, the measurement model and structural model assessment were performed (Hair et al., 2017). However, such a technique does not lead to non-linear and non-compensatory relationships. The artificial neural network (ANN) technique is more likely to conduct non-linear and noncompensatory relationships between variables (Albahri et al., 2021). Therefore, it is useful to use dual-stage PLS-SEM and ANN analysis for predicting and assessing the antecedents of using social commerce. This method aligns with much of the previous literature that strongly recommended identifying causal and non-compensatory relationships between constraints (e.g. Hew et al., 2016; Lee et al., 2020; Tan et al., 2014). Before the analyses, a common method bias test should be performed. According to Al-Abrrow et al. (2021b), respondents were informed their answers would be confidential. In addition, a five-point Likert scale was used, and other measures were used, such as age experience. Furthermore, there is no concern about the common method bias for this study. 


\section{Data analysis}

The data analysis process includes two steps. The first step involved analysing the causal relationships between the variables based on adopting the PLS-SEM technique. The second step includes analysing the non-compensatory and non-linear relationships between the variables using the ANN method.

\subsection{PLS-SEM analysis}

PLS-SEM analysis consists of assessing the measurement model and assessment of the structural model. The assessment of the measurement model involves convergent validity and discriminant validity. On the other hand, the structural model assessment includes a hypotheses test. Table. 1. Shown the convergent validity of this study. The convergent validity results indicated average variance extracted (AVE) values are above 0.50 , and the loadings factors are more than 0.70 . In addition, composite reliability (CR) is all above 0.70 (Hair et al., 2017).

Table 1 | Convergent validity

\begin{tabular}{|c|c|c|c|c|}
\hline Variables & Items & Loading & CR & AVE \\
\hline \multirow{4}{*}{ Social bond } & Item 1 & 0.781 & \multirow{4}{*}{0.901} & \multirow{4}{*}{0.694} \\
\hline & Item 2 & 0.848 & & \\
\hline & Item 3 & 0.855 & & \\
\hline & Item 4 & 0.847 & & \\
\hline \multirow{12}{*}{ Social network } & Item 1 & 0.832 & \multirow{12}{*}{0.948} & \multirow{12}{*}{0.606} \\
\hline & Item 2 & 0.844 & & \\
\hline & Item 3 & 0.781 & & \\
\hline & Item 4 & 0.763 & & \\
\hline & Item 5 & 0.814 & & \\
\hline & Item 6 & 0.821 & & \\
\hline & Item 7 & 0.757 & & \\
\hline & Item 8 & 0.704 & & \\
\hline & Item 9 & 0.809 & & \\
\hline & Item 10 & 0.779 & & \\
\hline & Item 11 & 0.713 & & \\
\hline & Item 12 & 0.796 & & \\
\hline \multirow{5}{*}{ Perceived risk } & Item 1 & 0.854 & \multirow{5}{*}{0.927} & \multirow{5}{*}{0.817} \\
\hline & Item 2 & 0.862 & & \\
\hline & Item 3 & 0.828 & & \\
\hline & Item 4 & 0.857 & & \\
\hline & Item 5 & 0.833 & & \\
\hline \multirow{6}{*}{$\begin{array}{c}\text { Convenience of adopting } \\
\text { wearable payment }\end{array}$} & Item 1 & 0.735 & \multirow{5}{*}{0.892} & \multirow{5}{*}{0.701} \\
\hline & Item 2 & 0.832 & & \\
\hline & Item 3 & 0.814 & & \\
\hline & Item 4 & 0.722 & & \\
\hline & Item 5 & 0.771 & & \\
\hline & Item 1 & 0.76 & 0.934 & 0.665 \\
\hline
\end{tabular}




\begin{tabular}{ccc} 
& Item 2 & 0.819 \\
Item 3 & 0.782 \\
Item 4 & 0.797 \\
\cline { 2 - 2 } Bem 5 & 0.702 \\
\hline Item 6 & 0.765 \\
payment & Item 7 & 0.714 \\
Item 8 & 0.712 \\
Item 9 & 0.728 \\
Item 10 & 0.749 \\
Item 11 & 0.783 \\
Item 12 & 0.776 \\
Item 13 & 0.778 \\
Item 14 & 0.747 \\
Item 15 & 0.759 \\
Intention to use social & Item 16 & 0.771 \\
Item 17 & 0.749 \\
\hline Item 1 & 0.84 \\
Item 2 & 0.847 \\
Item 3 & 0.872 \\
Item 4 & 0.826 \\
Item 5 & 0.744 \\
\hline
\end{tabular}

Source: authors' own calculations

In terms of discriminant validity, this study adopted the Fornell-Larker criterion test to assess discriminant validity. According to Hair et al. (2017), the square root values of the extracted AVE must be greater than the inter-construct correlations, as simplified in Table 2.

Table 2 | Discriminant validity

\begin{tabular}{lcccccc}
\hline \multicolumn{1}{c}{ Constructs } & $\mathbf{1}$ & $\mathbf{2}$ & $\mathbf{3}$ & $\mathbf{4}$ & $\mathbf{5}$ & $\mathbf{6}$ \\
\hline 1. Social bond & 0.833 & & & & & \\
2. Social network & 0.761 & 0.779 & & & & \\
3. Barriers of using wearable payment & 0.576 & 0.681 & 0.847 & & & \\
4. Perceived risk & 0.579 & 0.745 & 0.583 & 0.903 & & \\
5. Convenience of adopting wearable payment & 0.519 & 0.570 & 0.450 & 0.747 & 0.776 & \\
6. Intention to use social commerce & 0.334 & 0.472 & 0.305 & 0.745 & 0.756 & 0.827 \\
\hline
\end{tabular}

Source: authors' own calculations

Table 2 confirms that the square root values of the extracted AVE are greater than the interconstruct correlations. Therefore, there is no concern about discriminant validity. Moreover, it is possible to move to the second step of the PLS-SEM to the hypotheses test. We used a bootstrapping method based on PLS-SEM (Hair et al., 2017). To determine the significance of the path coefficients, we used the bootstrapping approach using 1000 (one-tailed, 0.05; 334 case data) bootstrap resampling and bias-corrected confidence intervals. At a $5 \%$ level 
of significance, the t-value for the one-tailed test must be equal to or greater than 1.645 (Hair et al., 2017). Table 3 illustrates the structural model assessment.

Table 3 | Assessment of structural model

\begin{tabular}{lcccccc}
\hline \multicolumn{1}{c}{ Path } & $\begin{array}{c}\text { Original } \\
\text { Sample }\end{array}$ & $\begin{array}{c}\text { Sample } \\
\text { Mean }\end{array}$ & $\begin{array}{c}\text { Standard } \\
\text { Deviation }\end{array}$ & $\begin{array}{c}\mathbf{T} \\
\text { Statistics }\end{array}$ & $\begin{array}{c}\mathbf{P} \\
\text { Values }\end{array}$ & Result \\
\hline SP -> CWP & 0.106 & 0.008 & 0.041 & 2.585 & 0.000 & Supported \\
SN -> CWP & 0.620 & 0.620 & 0.046 & 13.446 & 0.000 & Supported \\
CWP -> SC & 0.395 & 0.399 & 0.060 & 6.582 & 0.000 & Supported \\
SP -> CWP-> SC & 0.302 & 0.003 & 0.017 & 17.765 & 0.000 & Supported \\
SN -> CWP-> SC & 0.345 & 0.247 & 0.041 & 5.997 & 0.000 & Supported \\
PR ${ }^{*}$ SP -> CWP & 0.358 & 0.057 & 0.043 & 8.326 & 0.000 & Supported \\
PR ${ }^{*}$ SN -> CWP & 0.313 & 0.013 & 0.041 & 7.634 & 0.000 & Supported \\
BWP ${ }^{\star}$ CWP -> SC & 0.271 & 0.070 & 0.024 & 2.980 & 0.003 & Supported \\
\hline
\end{tabular}

Note: $\mathrm{SP}=$ Social bond; $\mathrm{SN}=$ Social network; $\mathrm{CWP}=$ Convenience of adopting wearable payment; $\mathrm{BWP}=$ Barriers of using wearable payment; $\mathrm{PR}=$ Perceived risk; $\mathrm{SC}=$ Intention to use social commerce.

\section{Source: authors' own calculations}

Table 3 shows a significant positive relationship between social bond, social network and convenience of adopting wearable payment $(\beta=0.106, t=2.585, p<0.05 ; \beta=0.620, t=$ 13.446, $p<0.05)$. Thus, hypotheses 1 and 2 are supported. In addition, the results showed the relationship between the convenience of adopting wearable payment and intention to use social commerce was statistically significant at the $5 \%$ significance level $(\beta=0.395, t=6.582$, $p<0.05)$. Hence, hypothesis 3 is acceptable. Therefore, convenience of adopting wearable payment has fully mediate the relationships between social bond, social network and intention to use social commerce $(\beta=0.302, t=17.765, p<0.05 ; \beta=0.345, t=5.997, p<$ $0.05)$. Accordingly, hypotheses 4 and 5 are supported. On the other hand, the relationships between social bond, social network and convenience of adopting wearable payment strong when perceived risk was high $(\beta=0.358, t=8.326, p<0.05 ; \beta=0.313, t=7.634, p<0.05)$. Consequently, hypotheses 6 and 7 are supported. Besides, the relationship between convenience of adopting wearable payment and intention to use social commerce was strong when barriers to using wearable payment were weak $(\beta=0.271, t=2.980, p<0.05)$. Thus, hypothesis 8 is supported. As mentioned previously, the PLS-SEM did not conduct a nonlinear relationship. Therefore, the ANN approach is needed. The next section explains the ANN analysis.

\subsection{ANN analysis}

ANN analysis based on multi-layer perceptron is adopted. According to the philosophy of ANN, which is based on deep learning, non-disjunctive and non-linear relationships are made between structures. Moreover, using the 'feed-forward back-propagation algorithm and Sigmoid as Activation Function, $90 \%$ of the data is adopted for training, and $10 \%$ is used for testing. In addition, this study used a ten-fold ANN. The weights of the supported variables 
were extracted in the PLS-SEM stage. Figure 2 and Table 4 illustrate the RMSE for training and testing processes in a ten-fold ANN.

Table 4 | RMSE for training and testing processes in a ten-fold ANN

\begin{tabular}{|c|c|c|c|c|c|c|c|}
\hline \multirow{3}{*}{ Neural Network } & \multicolumn{6}{|c|}{ Output nodes: Social Commerce } & \multirow{3}{*}{ Tota } \\
\hline & \multicolumn{3}{|c|}{ Training } & \multicolumn{3}{|c|}{ Testing } & \\
\hline & $\mathbf{N}$ & SSE & RMSE & $\mathbf{N}$ & SSE & RMSE & \\
\hline 1 & 296 & 372.695 & 0.422 & 38 & 62.448 & 0.632 & 334 \\
\hline 2 & 304 & 784.251 & 0.961 & 30 & 74.912 & 0.933 & 334 \\
\hline 3 & 302 & 653.202 & 0.805 & 32 & 76.789 & 0.969 & 334 \\
\hline 4 & 296 & 608.766 & 0.747 & 38 & 77.728 & 0.789 & 334 \\
\hline 5 & 292 & 469.526 & 0.507 & 42 & 76.522 & 0.619 & 334 \\
\hline 6 & 303 & 594.746 & 0.710 & 31 & 67.812 & 0.742 & 334 \\
\hline 7 & 294 & 599.496 & 0.738 & 40 & 78.956 & 0.750 & 334 \\
\hline 8 & 302 & 589.109 & 0.725 & 32 & 73.707 & 0.781 & 334 \\
\hline 9 & 295 & 539.718 & 0.705 & 39 & 82.181 & 0.821 & 334 \\
\hline 10 & 300 & 603.725 & 0.780 & 34 & 69.456 & 0.735 & 334 \\
\hline Mean & \multicolumn{2}{|c|}{581.524} & \multicolumn{2}{|c|}{0.0991473} & 74.051 & \multicolumn{2}{|c|}{0.081} \\
\hline SD & \multicolumn{2}{|c|}{108.488} & \multicolumn{2}{|c|}{0.150} & 5.895 & \multicolumn{2}{|c|}{0.112} \\
\hline
\end{tabular}

Source: authors' own calculations

Table 4 and Figure 2 show the predictive accuracy of the study model. Hence, low values of the root mean square of error (RMSE) indicate a high level of prediction accuracy. Moreover, the non-compensatory relationships are better explained according to the ANN method. Therefore, the social bond, social network, the convenience of adopting wearable payment, barriers of using wearable payment, and perceived risk are vital factors in increasing intention to use social commerce.

\section{Figure 2 | ANN model}

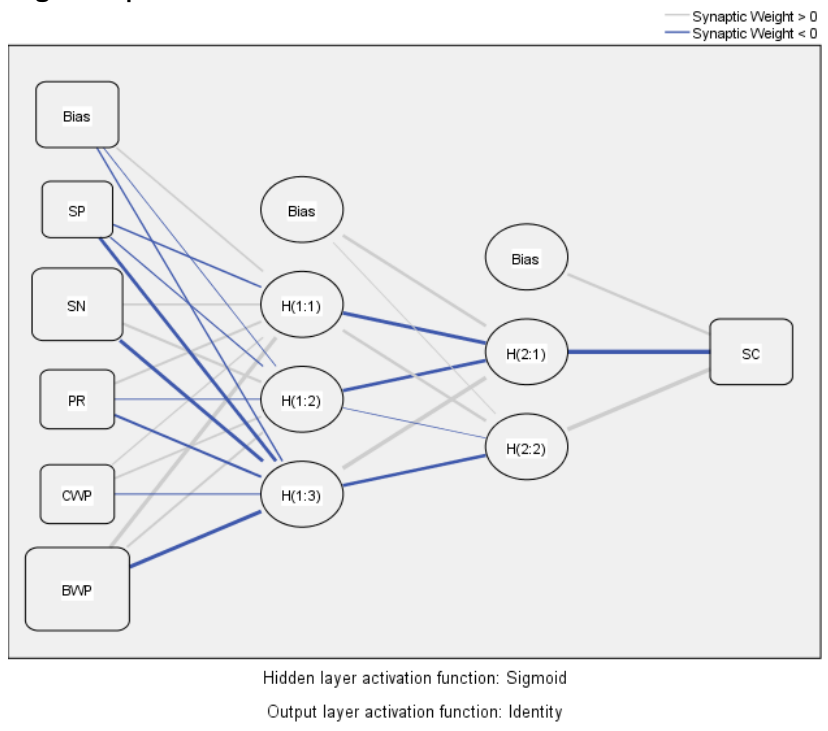

Source: authors' own elaboration 
This study adopted a sensitivity analysis based on the ANN method to determine the importance of using social commerce. Table 5 shows the importance of each determinant in social commerce.

Table 5 | Sensitivity analysis with normalised importance

\begin{tabular}{cccccc}
\hline \multirow{2}{*}{ Neural Network } & \multicolumn{5}{c}{ Relative importance } \\
\cline { 2 - 6 } & SP & SN & PR & CWP & BWP \\
\hline 1 & 0.171 & 0.225 & 0.184 & 0.169 & 0.251 \\
2 & 0.195 & 0.205 & 0.281 & 0.111 & 0.207 \\
3 & 0.166 & 0.174 & 0.103 & 0.277 & 0.280 \\
4 & 0.055 & 0.293 & 0.074 & 0.202 & 0.377 \\
5 & 0.169 & 0.231 & 0.131 & 0.114 & 0.355 \\
6 & 0.066 & 0.317 & 0.084 & 0.142 & 0.391 \\
7 & 0.107 & 0.275 & 0.060 & 0.150 & 0.409 \\
8 & 0.129 & 0.307 & 0.051 & 0.124 & 0.389 \\
9 & 0.142 & 0.233 & 0.130 & 0.154 & 0.341 \\
10 & 0.155 & 0.274 & 0.035 & 0.110 & 0.426 \\
Mean relative importance & 0.090 & 0.273 & 0.122 & 0.119 & 0.396 \\
Normalized importance (\%) & $22.7 \%$ & $68.9 \%$ & $30.7 \%$ & $30.1 \%$ & $100.0 \%$ \\
\hline
\end{tabular}

Note: $\mathrm{SP}=$ Social bond; $\mathrm{SN}=$ Social network; $\mathrm{CWP}=$ Convenience of adopting wearable payment; $\mathrm{BWP}=$ Barriers of using wearable payment; $\mathrm{PR}=$ Perceived risk

Source: authors' own calculations

Sensitivity analysis confirms that barriers to using wearable payment are limited to the use of social commerce, and this factor includes ease of use, expected effort, price, and so on. However, the social network is the second most important factor. Therefore, attention should be paid to customers' social presence by promoting immediate information and services for customers on websites.

\section{Discussion}

This study aims to conduct causal and non-linear relationships for predicting and assessing the antecedents of use of social commerce using dual-stage structural equation modelling and artificial neural network analysis. In addition, the relationship between the convenience of adopting wearable payment and intention to use social commerce was examined. Hence, the first objective is to examine the effect of social bonds and social networks on the convenience of adopting wearable payment. This study also aims to explore the role of the mediator of the convenience of adopting wearable payment for the relationship between social bonds and social networks and intention to use social commerce. On the other hand, the interactive roles of perceived risk and barriers of using wearable payment are explored. The results of the PLS-SEM confirmed the acceptance of all eight hypotheses mentioned in the Hypothesis Development section.

Because of its ramifications on the user experience, risk and trust are major considerations in electronic financial transactions such as wearables payment while using the platform. This cynicism not only affects consumers' intentions to embrace the platform but may also deter them from utilising it for future payments. Various studies have highlighted trust as a key factor in acceptance (Gao \& Waechter, 2017; Hampshire, 2017; Xin et al., 2015;) and actual 
use of this payment platform (Alnoor, 2020; Al-Abrrow et al., 2019). The current study intends to expand our research methodology by examining customers' readiness to accept wearable payment using social bond network theories. In this regard, Rodríguez and Wilson (2002) contend the perceived strength of social links positively influences trust in the business partner.

On the other hand, social commerce may be passed down through family, relatives, and friends. This is consistent with Kim-Soon et al. (2013). Trust may be transferred from a close individual or referent who shares something in common with the person receiving the trust. Furthermore, customers prefer to trust a service and are compelled to use it if a family member or referent does as well, and this is seen as an alternate sort of trust transmission. Online payment services and social network services are major items on mobile devices that impact our lives daily. We employ social network theory as a mechanism in this study because it emphasises the role of social linkages in conveying information, channelling personal or media effects, and promoting attitudinal or behavioural change (Wang et al., 2021). Social network theory provides a unique viewpoint and set of tools for comprehending media impacts. Furthermore, because most social connections are between friends, they have a higher level of confidence in one another (Yang et al., 2012). In this context, suggestions and interactions with friends might impact the users' usage context. For example, when buying something with friends, everyone usually uses the same payment method.

Payment via wearable devices has developed as a new technique. Wearable payments primarily involve payments and transactions conducted between two parties in a quick, convenient, secure, and simple manner, at any time and from any location, using smart wearable devices such as smartwatches, wristbands, fitness trackers, glasses, rings, key chains, and even jackets (Lee et al., 2020). The advantages of this payment system for companies and vendors include enhanced payment format adaptability for business transactions, higher flexibility in transactions over existing telephone networks, greater convenience, and time savings for both buyers and sellers. Wearable payment allows users to pay while on the go via smart wearable devices, which is like the notion of mobile payment. According to Lee et al. (2020), Wearable payment will bring in the next generation of mobile payments.

Wearable payments are riskier than traditional payment methods (such as cash) because they include storing and transferring personal and financial information through a wireless communication network. Furthermore, most people want their personal information (e.g. phone numbers, passwords, shopping history, and financial transactions) to be safe from possible privacy threats. Perceived risk combines uncertainty with the severity of the potential consequence. Privacy and financial risks are linked to the potential monetary and psychological losses caused by a lack of control over personal information. Customers utilise mobile payment authorised shops to access their bank accounts and use their personal information. As a result, customers may be concerned about possible dangers to their data, privacy, and transaction security. As a result, perceived performance risk is the likelihood that wearable devices will not work as intended. Because of the high level of uncertainty connected with wearable payments, trust becomes vital for a person to create confidence in an exchange partner. Trust builds among the parties involved in a technological transaction, perceived levels of risk fall and are neutralised. Yan et al. (2009) referred that confidence in 
service providers directly influences customer intent to utilise mobile payment services related to purchasing music downloads in Malaysia. According to Rouibah et al. (2016), confidence is the most crucial element influencing Kuwaitis' readiness to make electronic online payments. As a result, trust is an important factor in enhancing customers' behavioural intention to use wearable payments. Previous research has found trust has a considerable influence on behavioural intention in mobile payments, peer-to-peer m-payment (Kalinic et al., 2019), mobile wallets (Chawla \& Joshi, 2019; Shahrier et al., 2020), and mobile banking (Alalwan et al., 2017). As a result, perceived security has emerged as an essential additional factor in the context of social commerce.

\section{Theoretical implications}

This study contributes to researching the role of a group of different factors that represented the role of social link theory and social network theory and integrating both theories in the individual's intention to use social commerce and testing the extent of their impact on the individual's intention to adopt social commerce that takes place through a group of virtual sites via the Internet to buy products or services. In addition, this study deals with some variables that explain the reluctance or reinforcement of the individual's intention to adopt social commerce through what is related to the psychological needs of safety, privacy and ease.

The current study relied on very important axes divided into the social axis, which is represented by the theory of social link and social network theory, and the technological axis, which is represented by wearable means of payment (bracelets, rings, mobile phones and other smart technology) and the last axis that deals with the psychological aspect of individuals regarding how to think. The feelings associated with the use of social commerce, the significant role of perceived risk, the dynamic interaction between the psychological, social, and technological axis, and its ultimate influence on the individual's intention to use social commerce. We believe that the proposed integrated model, which consists of social elements, technological elements and psychological elements that were addressed in the study, can constitute a successful and accurate case as possible in terms of the model's ability to provide broad, comprehensive and accurate explanations towards business intelligence represented in the use of wearable payment and its interaction with psychological aspects and what is It is raised before and during the adoption of these technologies in addition to the effect of the social theories that were mentioned in restricting the behaviour of individuals and directing them towards the adoption of social commerce.

\section{Practical implications}

The practical contribution of this study is evident in making it possible to use the findings of the study in addition to what it shared with previous studies of organisations that work to exploit the opportunity represented in the ability to influence individuals to adopt social commerce through their actual use of social networking sites via the Internet or those companies Which has a future vision enhanced by sufficient willingness through which it plans to use these sites to achieve commercial purposes and try to understand why individuals may prefer to practice social commerce by identifying social trading sites and the means that allow them to conduct those commercial operations represented by wearable 
payment methods easily, and work on Design successful strategies accordingly to improve and develop their use.

In addition, many factors have been identified related to wearable payment methods that may enhance the intention of individuals to adopt social commerce due to the ease of conducting business operations and the necessary features related to it represented by privacy and security that enhances the confidence of individuals in adopting commerce. Therefore, this study recommends organisations in general that just creating social communities through the Internet is not enough and is not an important thing at all, because there are many other requirements for the success of this opportunity, for example, it is very important to have some advantages that are high privacy and security that allow trusting the high level of individuals in using them to conduct social business operations and to clarify this to individuals as much as possible. The existence of privacy, safety and means that facilitate social commerce operations without the knowledge and trust of individuals in them does not mean anything at all.

\section{Conclusion}

Social commerce is an emerging industry that makes a lot of profits. Moreover, previous literature confirms such an industry achieves huge annual use and profits. However, electronic payment is a vital barrier to intention to use social commerce. Therefore, this study highlighted an in-depth at the determinants of social commerce to predict and assess the antecedents of intention to use social commerce. A dual-stage structural equation modelling and artificial neural network analysis were adopted to determine causal and noncompensatory relationships between study constructs. This study explored the interactive roles of perceived risk and the barriers to using wearable payment. In addition, the effect of the mediating variable convenience of adopting wearable payment for the relationship of both social bonds and social networks to use social commerce was explored. The results of the PLS-SEM confirmed the support of all eight hypotheses mentioned in the Hypothesis Development section. However, ANN findings indicated that barriers to using wearable payment are limited to social commerce followed by the social network, which is the second most important factor. Consistent with any study, this study had several limitations. This study used a cross-sectional approach. Future studies can adopt a longitudinal approach to assess customers' behaviour towards social commerce. This study was also applied in Iraq. To our knowledge, no study combined multi-group PLS-SEM and ANN. Therefore, the application of such technology predicts the determinants and precedents of social commerce across different cultures between countries. Finally, new theories, such as electronic word of mouth, can be used.

\section{Acknowledgement}

This work is funded by Universiti Sains Malaysia, Short Term Grant [Grant Number: 304/PMGT/6315513], for the Project entitled "The Efficiency of Variable Sampling Interval Scheme for the Multivariate Coefficient of Variation in Short Production Runs". 


\section{References}

Abbas, S., Hadi, A. A., Abdullah, H. O., Alnoor, A., Khattak, Z. Z., \& Khaw, K. W. (2021). Encountering Covid-19 and perceived stress and the role of a health climate among medical workers. Current Psychology, 1-14. https://doi.org/10.1007/s12144-021-01381-8

Abdulaali, A. R., Alnoor, A., \& Eneizan, B. (2019). A multi-level study of influence financial knowledge management small and medium enterprises. Polish Journal of Management Studies, 19(1), 21 31. https://doi.org/10.17512/pjms.2019.19.1.02

Abdullah, H., Ismail, I., Alnoor, A., \& Yaqoub, E. (2021). Effect of perceived support on employee's voice behaviour through the work engagement: A moderator role of locus of control. International Journal of Process Management and Benchmarking, 11(1), 60-79. https://doi.org/10.1504/IJPMB.2021.112253

Akar, E., \& Dalgic, T. (2018). Understanding online consumers' purchase intentions: A contribution from social network theory. Behaviour \& Information Technology, 37(5), 473-487. https://doi.org/10.1080/0144929X.2018.1456563

Akers, R. L. (1997). Criminological theories: Introduction and evaluation (2nd ed.). Routledge.

Akers, R. L., Krohan, M. D., Lanza-Kaduce, L., \& Radosevich, M. (1979). Social learning deviant behavior: A specific test of a general theory. American Sociological Review, 44(4), 635-655. https://doi.org/10.2307/2094592

Al-Abrrow, H., Alnoor, A., \& Abbas, S. (2019). The effect of organisational resilience and CEO's narcissism on project success: Organisational risk as mediating variable. Organisation Management Journal, 16(1), 1-13. https://doi.org/10.1080/15416518.2018.1549468

Al-Abrrow, H., Fayez, A.S., Abdullah, H., Khaw, K. W., Alnoor, A., \& Rexhepi, G. (2021a). Effect of openmindedness and humble behavior on innovation: Mediator role of learning. International Journal of Emerging Markets. Article in press. https://doi.org/10.1108/IJOEM-08-2020-0888.

Al-Abrrow, H., Al-Maatoq, M., Alharbi, R.K., Alnoor, A., Abdullah, H.O., Abbas, S., \& Khattak, Z. Z. (2021b). Understanding employees' responses to the COVID-19 pandemic: The attractiveness of healthcare jobs. Global Business and Organizational Excellence, 40(2), 19-33. https://doi.org/10.1002/joe.22070

Albahri, A. S., Alnoor, A., Zaidan, A. A., Albahri, O. S., Hameed, H., Zaidan, B. B., ... \& Yass, A. A. (2021a). Hybrid artificial neural network and structural equation modelling techniques: A survey. Complex \& Intelligent Systems, 1(1), 1-21. https://doi.org/10.1007/s40747-021-00503-w

Albahri, A. S., Alnoor, A., Zaidan, A. A., Albahri, O. S., Hameed, H., Zaidan, B. B., ... \& Yass, A. A. (2021b). Based on the multi-assessment model: Towards a new context of combining the artificial neural network and structural equation modelling: A review. Chaos, Solitons \& Fractals, 153, 1-17. https://doi.org/10.1016/j.chaos.2021.111445

Albahri, A.S. (2022). Integration of fuzzy-weighted zero-inconsistency and fuzzy decision by opinion score methods under a q-rung orthopair environment: A distribution case study of COVID-19 vaccine doses. Computer Standards \& Interfaces, 80, 1-46. https://doi.org/10.1016/j.csi.2021.103572

Alhamdi, M., Noor, R. M. A. S., Abdulla, M., Alnoor, A., \& Eneizan, B. (2019). How does financial analysis influence the firm's failure of Iraqi private sector? The Journal of Social Sciences Research, 5(9), 1321-1328. https://doi.org/10.32861/jssr.59.1365.1374 
Alnoor, A. (2020). Human capital dimensions and firm performance, mediating role of knowledge management. International Journal of Business Excellence, 20(2), 149-168. https://doi.org/10.1504/IJBEX.2020.105357

Alnoor, A. M., Al-Abrrow, H., Abdullah, H., \& Abbas, S. (2020). The impact of self-efficacy on employees' ability to accept new technology in an Iraqi university. Global Business and Organizational Excellence, 39(2), 41-50. https://doi.org/10.1002/joe.21984

Alnoor, A., Abdullah, H. O., AL-Abrrow, H., Wah Khaw, K., Al-Awidi, I. A., Abbas, S., \& Omrane, A. (2021). A Fuzzy Delphi analytic job demands-resources model to rank factors influencing open innovation. Transnational Corporations

Review. https://doi.org/10.1080/19186444.2021.1956854

Alnoor, A., Al-Abrrow, H., Al Halbusi, H., Khaw, K.W., Chew, X., Al-Maatoq, M., \& Alharbi, R. K. (2022). Uncovering the antecedents of trust in social commerce: An application of the non-linear artificial neural network approach. Competitiveness Review. https://doi.org/10.1108/CR-04-2021-0051

Alsaleh, S., Nayak, R., Xu, Y., \& Chen L. (2011). Improving matching process in social network using implicit and explicit user information. In Du X., Fan W., Wang J., Peng Z. \& Sharaf M.A. (Eds.), Web Technologies and Applications. Lecture Notes in Computer Science (Vol. 6612, 305-311). Springer. https://doi.org/10.1007/978-3-642-20291-9_32

Atshan, N. A., Al-Abrrow, H., Abdullah, H. O., Khaw, K. W., Alnoor, A., \& Abbas, S. (2021). The effect of perceived organisational politics on responses to job dissatisfaction: The moderating roles of self-efficacy and political skill. Global Business and Organizational Excellence, 41(2), 43-54. https://doi.org/10.1002/joe.22141

Barnes, N. G. (2014). Social commerce emerges as big brands position themselves to turn 'follows', 'likes' and 'pins' into sales. American Journal of Management, 14(4), 11-18.

Bauer, R. (1967). Consumer behavior as risk taking. In D.F. Cox (Ed.), Risk taking and information handling in consumer behavior (23-33). Harvard University Press.

Bettman, J. (1973). Perceived risk and its components: A model and empirical test. Journal of Marketing Research, 10(2), 184-190. https://doi.org/10.2307/3149824

Beyari, H. M., \& Abareshi, A. (2019). The interaction of trust and social influence factors in the social commerce environment. In Advances in Intelligent Systems and Computing. Proceedings of the 3rd International Conference of Reliable Information and Communication Technology (IRICT 2018) (931-944.). Springer Link.

Bezhovski, Z. (2016). The future of the mobile payment as electronic payment system. European Journal of Business and Management, 8(8), 127-132.

Biucky, S. T., Abdolvand, N., \& Harandi, S. R. (2017). The effects of perceived risk on social commerce adoption based on tam model. International Journal of Electronic Commerce Studies, 8(2), 134157. https://doi.org/10.7903/ijecs. 1538

Boyd, D., \& Crawford, K. (2012). Critical questions for big data: Provocations for a cultural, technological, and scholarly phenomenon. Information, Communication \& Society, 15(5), 662-679. https://doi.org/10.1080/1369118X.2012.678878

Braojos, J., Benitez, J., \& Llorens, J. (2019). How do social commerce-IT capabilities influence firm performance? Theory and empirical evidence. Information and Management, 56(2), 155-171. https://doi.org/10.1016/j.im.2018.04.006

Burt, R.S. (1987). Social contagion and innovation: Cohesion versus structural equivalence. American Journal of Sociology, 92(6), 1287-1335. https://doi.org/10.1086/228667 
Burt, R.S. (1999). The social capital of opinion leaders. Annals of the American Academy of Political and Social Science, 566(1), 37-54. https://doi.org/10.1177/000271629956600104

Chen, J., \& Shen, X. L. (2015). Consumers' decisions in social commerce context: An empirical investigation. Decision Support Systems, 79, 55-64. https://doi.org/10.1016/j.dss.2015.07.012

Chen, P. T., \& Kuo, S. C. (2017). Innovation resistance and strategic implications of enterprise social media websites in Taiwan through knowledge sharing perspective. Technological Forecasting and Social Change, 118, 55-69. https://doi.org/10.1016/j.techfore.2017.02.002

Chuah, S. H. W., Rauschnabel, P. A., Krey, N., Nguyen, B., Ramayah, T., \& Lade, S. (2016). Wearable technologies: The role of usefulness and visibility in smartwatch adoption. Computers in Human Behavior, 65, 276-284. https://doi.org/10.1016/j.chb.2016.07.047

Cunningham, S. M. (1967). The major dimensions of perceived risk. In D.F. Cox (Ed.), Risk taking and information handling in consumer behaviour (82-108). Harvard University Press.

Das, A. K., Zeadally, S., \& Wazid, M. (2017). Lightweight authentication protocols for wearable devices.

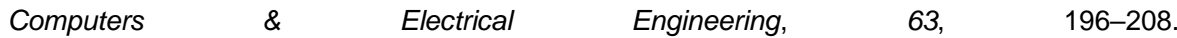
https://doi.org/10.1016/j.compeleceng.2017.03.008

Dowling, G., \& Staelin, R. (1994). A model of perceived risk and intended risk-handling activity. Journal of Consumer Research, 21(1), 119-134. https://doi.org/10.1086/209386

Dull, R. T. (1984). An empirical examination of the social bond theory of drug use. The International Journal of the Addictions, 19(3), 265-286. https://doi.org/10.3109/10826088409057181

Durkin, K., Wolfe, T., \& Clark, G. (1999). Social bond theory and binge drinking among college students: A multivariate analysis. College Student Journal, 33, 450-461.

Earl, J., \& Kimport, K. (2011). Digitally enabled social change: Activism in the internet age. MIT Press.

El Mhamdi, S., Wolfcarius-Khiari, G., Mhalla, S., Ben Salem, K., \& Soltani, S. M. (2011). Prevalence and predictors of smoking among adolescent schoolchildren in Monastir, Tunisia. Eastern Mediterranean Health Journal, 17(6), 523-528. https://doi.org/10.26719/2011.17.6.523

Eneizan, B., Mohammed, A. G., Alnoor, A., Alabboodi, A. S., \& Enaizan, O. (2019a). Customer acceptance of mobile marketing in Jordan: An extended UTAUT2 model with trust and risk factors. International Journal of Engineering Business Management, 11. https://doi.org/10.1177/1847979019889484

Eneizan, B. M., Abdelqader Alsakarneh, A. A., AL-kharabsheh, K. A., Hadi, A. L., \& Alnoor, A. (2019b). An investigation into the relationship between emotional labor and customer satisfaction. Central European Management Journal, 27(4), 23-47. https://doi.org/10.7206/cemj.2658-0845.8

Engel, J., Blackwell, R., \& Miniard, P. (1986). Consumer behavior. CBS College Publishing.

Enkel, E., Heil, S., Hengstler, M., \& Wirth, H. (2017). Exploratory and exploitative innovation: To what extent do the dimensions of individual level absorptive capacity contribute? Technovation, 60 61, 29-38. https://doi.org/10.1016/j.technovation.2016.08.002

Fadhil, S. S., Ismail, R., \& Alnoor, A. (2021). The influence of soft skills on employability: A case study on technology industry sector in Malaysia. Interdisciplinary Journal of Information, Knowledge, and Management, 16, 255-283. https://doi.org/10.28945/4807

Featherman, M. S., \& Pavlou, P. A. (2003). Predicting e-services adoption: A perceived risk facets perspective. International Journal of Human-Computer Studies, 59(4), 451-474. https://doi.org/10.1016/S1071-5819(03)00111-3 
Friedkin, N. E. (1993). Structural bases of interpersonal influence in groups: A longitudinal case study. American Sociological Review, 58(6), 861-872.

Gardner, L., \& Shoemaker, D. J. (1989). Social bonding and delinquency: A comparative analysis. Sociological Quarterly, 30(3), 481-499. https://doi.org/10.1111/j.1533-8525.1989.tb01532.x

Gibreel, O., Alotaibi, D. A., \& Altmann, J. (2018). Social commerce development in emerging markets. Electronic Commerce Research and Applications, 27, 152-162. https://doi.org/10.1016/j.elerap.2017.12.008

Hadi, A. A., Alnoor, A., \& Abdullah, H. O. (2018). Socio-technical approach, decision-making environment, and sustainable performance: Role of ERP systems. Interdisciplinary Journal of Information, Knowledge, and Management, 13, 397-415. https://doi.org/ 10.28945/4149

Hair, J. F., Ringle, C. M., \& Sarstedt, M. (2011). PLS-SEM: Indeed, a silver bullet. Journal of Marketing Theory and Practice, 19(2), 139-152. https://doi.org/10.2753/MTP1069-6679190202

Hair, J. F., Matthews, L. M., Matthews, R. L., \& Sarstedt, M. (2017). PLS-SEM or CB-SEM: Updated guidelines on which method to use. International Journal of Multivariate Data Analysis, 1(2), 107123. https://doi.org/10.1504/IJMDA.2017.087624

Hamid, R. A., Albahri, A. S., Alwan, J. K., Al-Qaysi, Z. T., Albahri, O. S., Zaidan, A. A., ... \& Zaidan, B. B. (2021). How smart is e-tourism? A systematic review of smart tourism recommendation system applying data management. Computer Science Review, 39, 100337. https://doi.org/10.1016/j.cosrev.2020.100337

Handarkho, Y. D. (2020). The intentions to use social commerce from social, technology, and personal trait perspectives: Analysis of direct, indirect, and moderating effects. Journal of Research in Interactive Marketing, 14(3), 305-336. https://doi.org/10.1108/JRIM-10-2018-0137

Hew, T. S., Leong, L. Y., Ooi, K. B., \& Chong, A. Y. L. (2016). Predicting drivers of mobile entertainment adoption: A two-stage sem-artificial-neural-network analysis. Journal of Computer Information Systems, 56(4), 352-370. https://doi.org/10.1080/08874417.2016.1164497

Hirschi, T. (1969). Causes of delinquency. University of California Press.

ıldırım, E., \& Erbay, A. (2021). Effects of school shooting on school climate: A review of social bond theory. The Bulletin of Legal Medicine, 26(1), 56-63. https//doi.org/10.17986/blm.149026

Jabbar, A. K., Almayyahi, A. R. A., Ali, I. M., \& Alnoor, A. (2020). Mitigating uncertainty in the boardroom: Analysis to financial reporting for financial risk COVID-19. The Journal of Asian Finance, Economics, and Business, 7(12), 233-243. https//doi.org/10.13106/jafeb.2020.vol7.no12.233

Jee, S. J., \& Sohn, S. Y. (2015). Patent network based conjoint analysis for wearable device. Technological Forecasting and Social Change, 101, 338-346. https://doi.org/10.1016/j.techfore.2015.09.018

Jeong, S. C., Kim, S. H., Park, J. Y., \& Choi, B. (2017). Domain-specific innovativeness and new product adoption: A case of wearable devices. Telematics and Informatics, 34(5), 399-412. https://doi.org/10.1016/j.tele.2016.09.001

Jia, J., Dyer, J. S., \& Butler, J. C. (1999). Measures of perceived risk. Management Science, 45(4), 519532. https://doi.org/10.1287/mnsc. 45.4 .519

Jin, A., Ling, D., \& Goh, A. (2004). Biohashing: Two factor authentication featuring fingerprint data and tokenised random number. Pattern Recognition, 37(11), 2245-2255. https://doi.org/10.1016/j.patcog.2004.04.011 
Kaipainen, V. (2015). Wearable payment for young women - Utilising rapid prototyping in iterative conceptual design [Master's thesis]. Aalto-University. https://aaltodoc.aalto.fi/handle/123456789/16588?show=full

Kaur, P., Dhir, A., Singh, N., Sahu, G., \& Almotairi, M. (2020). An innovation resistance theory perspective on mobile payment solutions. Journal of Retailing and Consumer Services, 55(12), 276-284. https://doi.org/10.1016/j.jretconser.2020.102059

Khaw, K. W., Alnoor, A., Al-Abrrow, H., Chew, X., Sadaa, A. M., Abbas, S., \& Khattak, Z. Z. (2022). Modelling and Evaluating Trust in Mobile Commerce: A Hybrid Three Stage Fuzzy Delphi, Structural Equation Modeling, and Neural Network Approach. International Journal of HumanComputer Interaction, Articl in press, 1-17.

Khaw, W., Ramayah, T., AL-Abrrow, H., Alnoor, A., Tiberius, V., Abdullah, H., \& Abbas, S. (2022b). Influence of generational status on immigrants' entrepreneurial intentions to start new ventures: A framework based on structural equation modelling and multicriteria decision-making. Journal of Entrepreneurship in Emerging Economies. https://doi.org/10.1108/JEEE-04-2021-0141

Kim, S., \& Park, H. (2013). Effects of various characteristics of social commerce (s-commerce) on consumers' trust and trust performance. International Journal of Information Management, 33(2), 318-332. https://doi.org/10.1016/j.jinfomgt.2012.11.006

Kotler, P. (1996). Marketing management (8th ed.). Prentice Hall.

Krause, J., Croft, D. P., \& James, R. (2007). Social network theory in the behavioural sciences: Potential applications. Behavioral Ecology and Sociobiology, 62, 15-27. https://doi.org/10.1007/s00265007-0445-8

Krishnan, E., Mohammed, R., Alnoor, A., Albahri, O. S., Zaidan, A. A., Alsattar, H., \& Alazab, M. (2021). Interval type 2 trapezoidal-fuzzy weighted with zero inconsistency combined with VIKOR for evaluating smart e-tourism applications. International Journal of Intelligent Systems, 36(9), 4723-4774. https://doi.org/10.1002/int.22489

Lal, P. (2017). Analysing determinants influencing an individual's intention to use social commerce website. Future Business Journal, 3(1), 70-85. https://doi.org/10.1016/j.fbj.2017.02.001

Lamkin, P. (2016). Wearable Tech Market to Be Worth $\$ 34$ Billion By 2020. Forbes.com. https://www.forbes.com/sites/paullamkin/2016/02/17/wearable-tech-market-to-be-worth-34billion-by-2020/?sh=7c904ad13cb5

Lee, V. H., Hew, J. J., Leong, L. Y., Tan, G. W. H., \& Ooi, K. B. (2020). Wearable payment: A deep learning-based dual-stage SEM-ANN analysis. Expert Systems with Applications, 157, 113477. https://doi.org/10.1016/j.eswa.2020.113477

Leong, L. Y., Hew, T. S., Ooi, K. B., \& Wei, J. (2020). Predicting mobile wallet resistance: A two-staged structural equation modeling-artificial neural network approach. International Journal of Information Management, 51, 102047. https://doi.org/10.1016/j.jinfomgt.2019.102047

Lewis, S. C., Zamith, R., \& Hermida, A. (2013). Content analysis in an era of big data: A hybrid approach to computational and manual methods. Journal of Broadcasting \& Electronic Media, 57(1), 34 52. https://doi.org/10.1080/08838151.2012.761702

Liang, T. P., \& Turban, E. (2011). Introduction to the special issue social commerce: A research framework for social commerce. International Journal of Electronic Commerce, 16(2), 5-14. https://doi.org/10.2753/JEC1086-4415160201

Lu, B., Fan, W., \& Zhou, M. (2016). Social presence, trust, and social commerce purchase intention: Empirical research. Computers in Human Behavior, 56, 225-237. https://doi.org/10.1016/j.chb.2015.11.057 
Ma, L., \& Lee, C. S. (2019). Understanding the barriers to the use of MOOCs in a developing country: An innovation resistance perspective. Journal of Educational Computing Research, 57(3), 571590. https://doi.org/10.1177/0735633118757732

Mardsen, P. (2010). Social commerce: Monetising social media. GRIN Verlag.

Mitchell, V. (1992). Understanding consumers' behaviour: Can perceived risk theory help? Management Decision, 30(3), 26-34. https://doi.org/10.1108/00251749210013050

Moeller, J. (2017). Touch-triggered payment using a wearable device. Technical Disclosure Commons. https://www.tdcommons.org/cgi/viewcontent.cgi?article=1613\&context=dpubs_series

Nel, J., \& Boshoff, C. (2020). Status quo bias and shoppers' mobile website purchasing resistance. European Journal of Marketing, 54(6), 1433-1466. https://doi.org/10.1108/EJM-02-2018-0144

$\mathrm{Ng}, \mathrm{C}$. S. P. (2013). Intention to purchase on social commerce websites across cultures: A cross-regional study. Information and Management, 50(8), 609-620. https://doi.org/10.1016/j.im.2013.08.002

Ogan, C., \& Varol, O. (2016). What is gained and what is left to be done when content analysis is added to network analysis in the study of a social movement: Twitter use during Gezi Park. Information, Communication \& Society, 20(8), 1220-1238. https://doi.org/10.1080/1369118X.2016.1229006

Perry, M., \& Hamm, B. C. (1969). Canonical analysis of relations between socioeconomic risk and personal influence in purchase decisions. Journal of Marketing Research, 6(3), 351-354. https://doi.org/10.2307/3150142

Peter, J., \& Ryan, M. (1976). An investigation of perceived risk at the brand level. Journal of Marketing Research, 13(2), 184-188. https://doi.org/10.2307/3150856

Rabaa'i, A., \& Zhu, X. (2021). Understanding the determinants of wearable payment adoption: An empirical study. Interdisciplinary Journal of Information, Knowledge \& Management, 16, 173211. https://doi.org/10.28945/4746

Ram, S., \& Sheth, J. N. (1989). Consumer resistance to innovations: The marketing problem and its solutions. The Journal of Consumer Marketing, 6(2), 5-14. https://doi.org/10.1108/EUM0000000002542

Roselius, T. (1971). Consumer rankings of risk reduction methods. Journal of Marketing, 35(1), 56-61. https://doi.org/10.2307/1250565

Schroeder, R. D. (2016). Social bond theory. In W.G. Jennings (Ed.), The encyclopedia of crime and punishment. John Wiley \& Sons.

Scott, J. (1991). Social network analysis: A handbook. Sage.

Shanka, M. S., \& Buvik, A. (2019). When does relational exchange matters? Social bond, trust and satisfaction. Journal of Business-to-Business Marketing, 26(1), 57-74. https://doi.org/10.1080/1051712X.2019.1565137

Shanmugam, M., Sun, S., Amidi, A., Farzad, K., \& Fariborz, K. (2016). The applications of social commerce construct. International Journal of Information Management, 36(3), 425-432. https://doi.org/10.1016/j.ijinfomgt.2016.01.007

Sharma, S., Menard, P., \& Mutchler, L. A. (2018). Who to trust? Applying trust to social commerce. Journal of Computer Information Systems, 59(1), 32-42. https://doi.org/10.1080/08874417.2017.1289356

Shoemaker, D. J. (1996). Theories of delinquency: An examination of explanations of delinquent behavior (3rd ed.). Oxford University Press. 
Tan, G. W. H., Ooi, K. B., Leong, L. Y., \& Lin, B. (2014). Predicting the drivers of behavioral intention to use mobile learning: A hybrid SEM-Neural Networks approach. Computers in Human Behavior, 36, 198-213. https://doi.org/10.1016/j.chb.2014.03.052

Tariq, B., Najam, H., Han, H., Sadaa, A. M., Abbasi, A. A., Christopher, N., \& Abbasi, G. A. (2021). Examining mobile financial services in Pakistan: Rural and urban perspective with gender as a moderator. In Recent advances in technology acceptance models and theories (pp. 225-245). Springer, Cham.

Taylor, J. W. (1974). The role of risk in consumer behavior. Journal of Marketing, 38(2), 54-60. https://doi.org/10.1177/002224297403800211

Wang, C., \& Zhang, P. (2012). The evolution of social commerce: The people, management, technology, and information dimensions. Communications of the Association for Information Systems, 31(5), 105-127. https//doi.org/10.17705/1CAIS.03105

Liu, W., Sidhu, A., Beacom, A. M., \& Valente, T. (2017). Social network theory. In P. Rössler (Ed.), The international encyclopedia of media effects. John Wiley \& Sons.

Yadav, M. S., De Valck, K., Hennig-Thurau, T., Hoffman, D. L., \& Spann, M. (2013). Social commerce: A contingency framework for assessing marketing potential. Journal of Interactive Marketing, 27(4), 311-323. https://doi.org/10.1016/j.intmar.2013.09.001

Zaltman, G., \& Wallendorf, M. (1983). Consumer behavior. John Wiley \& Sons.

Zhang, J., Liu, H., Sayogo, D. S., Picazo-Vela, S., \& Luna-Reyes, L.F. (2016). Strengthening institutionalbased trust for sustainable consumption: Lessons for smart disclosure. Government Information Quarterly, 33(3), 552-561. 10.1016/j.giq.2016.01.009

The research article passed the review process. | Received: April 11, 2021; Revised: January 31, 2022; Accepted: February 4, 2022; Prepublished online: March 7, 2022; Published in the regular issue: December 2, 2022. 